$\$$ sciendo

\title{
Um Filósofo da Evidência
}

M. S. Lourenço

LanCog, Universidade de Lisboa

Disputatio Vol. 3, No. 27

November 2009

DOI: 10.2478/disp-2009-0010

ISSN: 0873-626X 


\title{
Um filósofo da evidência*
}

\author{
M. S. Lourenço \\ Universidade de Lisboa
}

Embora algumas posições filosóficas de Gödel sejam bem conhecidas, como o platonismo, a sua teoria do conhecimento é, em comparação, menos divulgada. A partir do «Problema da Evidência» de HilbertBernays, I, pg. 20 seq., apresento a seguir os traços essenciais da posição de Gödel sobre a caracterização epistemológica da evidência finitista, com especial relevo para a história dos conceitos utilizados.

Embora Gödel tenha lido Filosofia desde o ensino secundário e depois na Universidade de Viena tenha frequentado o Círculo de Viena, o seu interesse profissional pela disciplina parece ter apenas acordado nos anos sessenta. Numa carta a Bernays datada de 1968, e numa referência ao seu trabalho de $1958^{1}$, Gödel afirma que nesta data o seu objectivo predominante era de carácter matemático, em contraste com a posição em 1968, em que o conteúdo filosófico do problema da extensão veio ocupar o lugar do primitivo objectivo matemático.

Mas as posições filosóficas de Gödel assemelham-se aos enigmas daqueles filósofos da Antiguidade cujo pensamento só se conhece pela interposição de um segundo autor, o qual relata, com um inverificável grau de fiabilidade, as teses do primeiro. No caso de Gödel tem indubitavelmente esse papel Hao Wang, e é com o recurso aos seus livros que se pode reconstituir um esboço do que são as teses filosóficas de Gödel. O próprio Hao Wang tem uma judiciosa classificação dos escritos de Gödel em três áreas: uma área nuclear é constituída pelos resultados matemáticos de Gödel, e duas áreas adjacentes, uma com as projeç̧ões (para o futuro) de uma disciplina de Filosofia, na expressão de Brentano, como ciência de rigor, tipificada por uma teoria axiomática dos conceitos básicos da Metafísica, e uma outra de reflexões sobre temas heterogéneos como a origem da vida, a irrealidade (2006).

* Originalmente publicado no Boletim da Sociedade Portuguesa de Matemática, 55

${ }^{1}$ Kurt Gödel (1958), «Über eine bisher noch nicht benützte Erweiterung des finiten Standpunktes», Dialectica 12, pp. 280-287.

Disputatio, Vol. III, No. 27, November 2009 
do tempo segundo Leibniz e Einstein e o então novo círculo de problemas sobre a eventual mecanização do pensamento.

Para a identificação das teses de Gödel é assim preciso lançar mão não só dos seus escritos publicados e dos seus escritos não publicados, como também dos relatos dos seus alunos sobre a posição de Gödel em problemas filosóficos específicos, uma posição por vezes apenas articulada em entrevista ou em discussão com um restrito grupo de pessoas. ${ }^{2}$

É útil, antes de entrar propriamente na concepção de Gödel da caracterização do conceito de evidência, ter uma descrição de algumas das suas outras teses, em particular a definição de um método para a filosofia e o problema da união desta com a ciência.

Como segundo Gödel a filosofia actual está, para o ideal da ciência de rigor, no estado em que se encontrava a Física antes da obra de Newton, é de começar com a teoria (ou a projeç̧ão) da Análise Conceptual como o método da filosofia do futuro, da filosofia como ciência de rigor.

Uma primeira concepção da Filosofia como ciência de rigor e análise de conceitos apareceu na obra de Franz Brentano, cujo estilo filosófico era o oposto, quer pela forma reflectida quer pelo conteúdo preciso, do idealismo alemão. Para Brentano o uso da linguagem em filosofia não se deve afastar do uso da linguagem na ciência e ele foi, depois do ideal de Leibniz da philosophia mathematica e antes de Gödel, o mais enérgico defensor da tese segundo a qual o verdadeiro método da filosofia é o método da ciência e reciprocamente.

Extensionalmente um conceito é uma função (linguística) cujo domínio é um conjunto de objectos, chamado o domínio do conceito, e cujo valor é um único elemento do conjunto dos dois valores de verdade, verdadeiro e falso. Intensionalmente um conceito é o sentido do termo predicativo pelo qual o conceito é representado.

Os conceitos são o objecto em investigação na Análise Conceptual.

A função básica em Análise Conceptual é para Gödel a percepção de conceitos, os quais são susceptíveis de ser conhecidos com o mesmo grau de fiabilidade com que conhecemos os objectos do mundo exte-

\footnotetext{
${ }^{2}$ Gödel teve consciência de estar em oposição ao «espírito do tempo» (ao que ele chama Zeitgeist) e recusou por isso dar a conhecer as suas teses em Filosofia, por recear ter um público desfavorável. Mas com Bernays, que conhecia com detalhe a filosofia de Brentano e de Husserl, Gödel teve discussões prolongadas ainda antes de 1958. (Brentano exerceu a sua influência também em Zurique, onde teve uma cátedra desde a sua emigração de Viena até 1918).
} 
rior. A percepção de conceitos pode ser ensinada e é possível corrigir gradualmente o grau de fiabilidade com que um conceito é percepcionado. O instrumento adequado para essa correcção é justamente a história conceptual, onde a evolução do conceito é investigável. Assim os conceitos descobertos pela nossa percepção evoluem à medida que a própria percepção evolui.

Exemplo: A proposição «Todos os conjuntos são construtíveis» foi numa ocasião considerada por Gödel como um axioma e mais tarde considerado como sendo uma proposição falsa.

A finalidade da Análise Conceptual é a transformação de um conceito vago num conceito preciso. Há diversos paradigmas da Análise de Conceitos e embora Gödel tenha favorecido sempre como paradigmas a análise de Dedekind do conceito de «número» e a análise de Turing do conceito de «função calculável», é óbvio que Gödel 1958 pode também servir como paradigma de análise, neste caso do conceito de função calculável de tipo finito.

Uma Análise de Conceitos é representada num sistema de axiomas: se o sistema de axiomas tem um modelo então os conceitos que ocorrem no sistema são precisos; a fortiori se uma teoria axiomática é categórica, os conceitos analisados nos axiomas são conceitos precisos.

Existe uma diferença gradual entre a percepção de pequenos conjuntos de números e a percepção dos números naturais como uma totalidade acabada. A idealização é o instrumento necessário para passar de uma para a outra forma de percepção. Gödel concebe a idealização como sendo uma função de síntese, tal como esta é definida por Kant na Crítica da Razão Pura, onde o conceito de uma totalidade (infinita) é identificado com a representação da síntese perfeita das partes, uma vez que esta síntese não pode vir da percepção do todo infinito (uma percepção que por definição não existe), com a reiteração desta síntese das partes até ao infinito. A percepção do conjunto dos números naturais como uma totalidade é assim o resultado do exercício da actividade de síntese, melhor definida no $§ 18$ da Crítica da Razão Pura como sendo a unidade transcendental da apercepção, a qual unifica no conceito de um objecto tudo o que na intuição nos é dado como uma multiplicidade.

A estabilidade da teoria clássica dos números garante a objectividade das nossas percepções relativamente aos números naturais. É claro que o conceito de percepção tem que ser generalizado de modo a incluir também a percepção de conceitos e em particular a percepção de conceitos a partir da perspectiva certa, como foi exemplificado pela 
definição de Turing do conceito de «processo mecânico». É este género de percepção que Gödel designa por intuição matemática.

Mas a intuição matemática de Gödel é diferente da evidência intuitiva de Hilbert. Hilbert tinha-se apoiado na definição bipartida de Kant na Crítica da Razão Pura $(113,175)$ em particular na sua análise da intuição sensível. ${ }^{3}$ Esta é apresentada em duas formas, a pura e a empírica e enquanto ambas se desenvolvem no quadro espaçotempo, só a intuição empírica se relaciona com um objecto por meio de uma sensação.

Nestes termos, a percepção de objectos de segunda ordem, como conceitos ou como os funcionais recursivos de Gödel 1958 não caem dentro dos limites da evidência intuitiva de origem kantiana. Em última análise as definições de Gödel são incompatíveis com a adopção das teorias causais gémeas, a teoria causal da percepção e a teoria causal do conhecimento, uma vez que não se pode supor que objectos de segunda ordem actuem causalmente sobre o sujeito cognitivo. ${ }^{4}$

Os conjuntos e os conceitos são as entidades básicas da ontologia de Gödel. Conjuntos puros são os que se obtêm começando com o conjunto vazio e depois reiterando a operação «o conjunto de...».

Os conceitos são funções e relacionam-se com os conjuntos através da extensão do conceito. A relação de «pertença» é para um conjunto o que a relação de «estar na extensão de...» é para um conceito. Os conjuntos e os conceitos são ambos aspectos da realidade objectiva. Os números são também parte da realidade e assim num termo como «as 7 cores do arco-íris» fazem parte da realidade objectiva não só as cores (vermelho, amarelo, etc.) como também o número 7.

À existência objectiva dos objectos matemáticos corresponde a objectividade do nosso conhecimento acerca deles. Esta objectividade exprime-se num conceito de verdade para o qual o Tertium non Datur é válido ou, equivalentemente, na convicção de que, por exemplo, a Conjectura de Goldbach é verdadeira ou falsa. Assim os objectos

${ }^{3}$ A tradução do termo de Kant «Anschauung» por «intuição» é desvantajosa, porque na linguagem corrente o sentido do termo «intuição» é em geral compreendido como «ter sorte a adivinhar».

${ }^{4}$ Para uma tentativa de conciliação ver P. Maddy, «Perception and Mathematical Intuition», The Philosophical Review, LXXXIX, N. 2, (April 1980). Deve-se no entanto ter em conta que o projecto de P. Maddy depende da concepção de conjunto como um «indivíduo» e não como um objecto abstracto. 
matemáticos não são apenas nomes ou construções arbitrárias do sujeito cognitivo.

Mas embora nós tenhamos uma percepção destes objectos, as nossas ideias sobre as suas propriedades são por sua vez formadas na base ainda de algo muito diferente, nomeadamente na base de um conjunto de verdades que nos é imediatamente dado, o qual Gödel qualifica com o termo tradicional de «evidente».

Na literatura filosófica o termo «evidência» é usado em dois sentidos diferentes: num primeiro sentido, corrente em filosofia da ciência, o termo cobre o conjunto dos objectos e das relações que apoiam uma hipótese científica e ocorre neste sentido em expressões como «evidência empírica» ou «evidência estatística»; num segundo sentido, o sentido usado por Hilbert-Bernays e por Gödel 1958, o termo provém da tradição da teoria escolástica da intencionalidade e da existência de cognição intuitiva, uma teoria desenvolvida essencialmente pelos lógicos de Oxford no século XIV, o platonista Duns Escoto e o nominalista William Ockham, e a qual é proposta para explicar a experiência de uma verdade como indubitável, ou como uma evidência. Mas a análise da evidência de Hilbert-Bernays, que Gödel retoma no seu ensaio 1958, é um estádio posterior da teoria neo-escolástica de Brentano, o qual adapta as posições de Escoto na intencionalidade, e de Escoto e Ockham na evidência, a uma ontologia anti-realista.

Para identificar a intencionalidade ${ }^{5}$ dos actos da mente Duns Escoto parte do facto de que somos capazes de reflectir sobre os nossos próprios actos e que obtemos assim, através desta auto-reflexão, a concepção de um sujeito cognoscente. Este acto de auto-reflexão é o resultado de uma função da mente. Assim é possível conhecer os objectos visados pelos actos da mente, isto é, a sua intencionalidade, mesmo quando estes objectos estão no momento ausentes da mente. Diz-se então que estes objectos são mentalmente inexistentes, mas alcan-

\footnotetext{
${ }^{5}$ «Intencionalidade» denotará a seguir uma relação binária entre um estado mental e o seu objecto (ou conteúdo). Exemplos: (O estado mental em itálico) 1) $\mathrm{O}$ que Frege queria dizer com «a estrela da manhã» era a deusa do amor e não o planeta Vénus; 2) Uma pessoa $A$ quer dizer com «virtude» o que uma pessoa $B$ quer dizer com «vício». As suas propriedades essenciais são: i) a relação é dada pelo sentido fregiano dos termos, i.e., pelo seu modo de apresentação; ii) a relação obtém sem implicação existencial para o $2 .^{\circ}$ argumento; iii) a expressão da relação cria um contexto intensional, logo sem substituição salva veritate.
} 
çáveis intencionalmente. Obviamente este conhecimento só é possível se se postular a existência do acto de auto-reflexão. Na verdade a existência deste acto é-nos dada na experiência e o facto da autoreflexão implicita a existência da função mental que a realiza e a que se chama intuição. Assim o acto de auto-reflexão ensina-nos que possuímos conhecimento de propriedades de objectos as quais são reconhecíveis por uma função da mente, a intuição, mesmo quando estes objectos são mentalmente inexistentes.

Para Duns Escoto a experiência da intuição mostra-nos que podemos alcançar o conhecimento de objectos abstractos (ou universais). $\mathrm{Na}$ verdade podemos conhecer um conceito e alguns dos seus aspectos, como o seu sentido, de um modo completamente diferente do que conhecemos os objectos das nossas percepções sensíveis e sem qualquer intervenção de uma faculdade dos sentidos. A experiência intuitiva também nos revela a existência de relações que obtêm entre objectos, mesmo quando estes objectos não são percepcionados pelos sentidos. Temos sobretudo um conhecimento intuitivo do próprio acto por meio do qual conhecemos estes diferentes objectos, como um acto interno, que tem lugar na nossa própria mente. E assim vemo-nos a dar o nosso assentimento a juízos imunes a dúvida ou a contraexemplo, quando por exemplo aceitamos axiomas como evidentes.

Foi Duns Escoto quem primeiro fez a distinção entre cognição intuitiva e cognição abstractiva: com a primeira predica-se o conhecimento acerca de um objecto existente, (por exemplo, com coordenadas espaço-tempo), pela segunda a existência do objecto não é parte do conhecimento predicado pelo termo. A cognição intuitiva pode predicar o conhecimento não só acerca dos objectos (materiais) do mundo exterior como também acerca dos objectos (imateriais) da actividade mental. Mas a cognição abstractiva não pode garantir a certeza indubitável dos nossos juízos sobre objectos existentes, quer os materiais no mundo exterior quer os imateriais no mundo interior. $\mathrm{Na}$ verdade só a cognição intuitiva torna possível a introspecção como intuição dos objectos do mundo interior e a evidência como um predicado de um juízo verdadeiro.

Para um nominalista como Ockham, de acordo com o princípio de que o todo é apenas a união das partes, o conhecimento de uma proposição verdadeira é considerado como evidente se e somente se o modo de conhecer o sentido dos termos produz o modo de conhecer o sentido da proposição (verdadeira). Assim é o modo (não o conteú- 
do) como os termos de uma proposição são dados a conhecer que determina se a proposição é ou não evidente.

A posição de Ockham ilustra-se bem através da distinção entre proposições necessárias e contingentes. O resultado geral é que uma proposição necessária é evidente mas que nem todas as proposições evidentes são necessárias. Se uma proposição é necessária qualquer das formas de conhecimento (intuitivo ou abstractivo) é suficiente para garantir a evidência da proposição. Mas no caso de uma proposição contingente só o conhecimento intuitivo dos termos da proposição produz a evidência da proposição. Assim se se abstrair da questão da existência ou não existência do objecto (de conhecimento), seguese que não se pode ter conhecimento evidente de asserções existenciais acerca deste objecto. Logo para explicar o facto de que consideramos algumas proposições existenciais como evidentes é necessário admitir a existência de uma outra forma de conhecimento, o conhecimento intuitivo. O conhecimento intuitivo é uma relação directa entre a mente e o objecto, sem recurso à mediação por um conceito. É para Ockham geneticamente a primeira forma de conhecimento. Como para um nominalista as únicas coisas reais são indivíduos, o conhecimento começa com o conhecimento de indivíduos. Não se parte do universal para o indivíduo; começa-se com indivíduos e determina-se a seguir em que sentido é que os conceitos que obtemos com eles são universais. Uma forma diferente de conhecimento é obtida pela cognição abstractiva, a qual permite passar do conhecimento de indivíduos para o conhecimento de um conceito (ou um universal) pela exclusão de juízos de existência (ou de diferenças individuais). Mas tal como Duns Escoto, Ockham pensa que a cognição intuitiva produz um grau mais elevado de evidência.

No século XIX a polémica contra a caracterização de Kant do juízo aritmético como um juízo sintético foi bem representada por Franz Brentano, o qual concebeu e realizou o projecto de uma definição, a que ele chamou empirista, do conceito de verdade.

Como para Brentano a introspecção é um método fiável de investigação, pode-se generalizar o conceito de experiencia de modo a incluir os resultados da introspecção, sob a forma de uma descrição dos fenómenos da mente, ${ }^{6}$ em particular dos actos mentais. A relação entre um acto da mente e o seu objecto faz daquele um acto intencio-

${ }^{6}$ Equivale por isso ao sentido do termo inglês experience. 
nal. Actos mentais em particular e fenómenos mentais em geral são para Brentano definidos como aqueles fenómenos que referem de um modo intencional (ou apenas mental) um conteúdo ou um objecto, mesmo quando está mentalmente inexistente.

Um acto mental distingue-se dum acto físico, (como pregar um prego na parede), pelo facto de a relação entre o acto físico e o seu conteúdo ser uma relação externa e a relação entre um acto mental (como duvidar que Pedro negou Cristo) e o seu conteúdo ser uma relação interna. Em particular a intencionalidade de um acto mental é constituinte do acto, a sua alteração produz um outro acto.

Exemplo: «Duvidar que Pedro negou Cristo». Negar Cristo está com Pedro numa relação interna, porque negar Cristo é constituinte da identidade de Pedro.

Isto é na verdade um corolário da doutrina de Leibniz de que um objecto é determinado pela soma dos seus predicados. Assim para ver que negar Cristo está com Pedro numa relação interna basta provar que não podem existir duas situações com os mesmos objectos, a situação $S_{1}$, em que Pedro nega Cristo e a situação $S_{2}$ em que Pedro não nega Cristo. (No exemplo o Pedro de $S_{2}$ é diferente do Pedro de $S_{1}$, visto ser igual a «o Pedro de $S_{1}$ menos negar Cristo» e o Cristo de $S_{2}$ é diferente do Cristo de $S_{1}$, visto ser igual a «o Cristo de $S_{1}$ menos a negação de Pedro».)

Em geral defende-se que uma tal relação é uma relação necessária, expressa pela implicação «se Pedro nega Cristo então necessariamente Pedro nega Cristo». ${ }^{7}$

Os actos mentais são descritos por verbos transitivos como por exemplo «pensar que $P_{\gg}$, «constatar que $P_{\gg}$, «duvidar que $P_{\gg}$, etc. e aquilo que se pensa, se constata ou se duvida é o conteúdo intencional do acto de pensar, constatar ou duvidar. Assim para Brentano constatar a evidência da verdade de $P$ é equivalente a aceitar que $P$ é irrefutável por meio de um contra-exemplo.

Brentano propõe uma classificação dos juízos, rival da classificação de Kant, de modo a separar três classes fundamentais: juízos formados a partir de uma percepção, juízos formados a partir de uma memória e os juízos incorporados em axiomas.

\footnotetext{
${ }^{7}$ Contra relações internas em geral e a sua interpretação modal em particular ver G. E. Moore, «External and Internal Relations», Proceedings of the Aristotelian Society, 1919-1920.
} 
Como há duas formas de percepção para Brentano, a percepção dos fenómenos físicos e a percepção dos fenómenos da mente, os juízos formados a partir de percepções dão origem a duas subclasses correspondentes. Mas só a verdade dos juízos formados a partir da percepção dos fenómenos da mente e a verdade dos axiomas pode ser considerada como evidente. A verdade de um juízo formado a partir de uma memória não pode ser considerada como evidente.

Adaptando a distinção de Leibniz entre verdades de razão e verdades de facto, Brentano distingue a evidência apodítica, que resulta dos axiomas através da análise do sentido dos conceitos que ocorrem no juízo verdadeiro, da evidência imediata, como a que é obtida na introspecção. Entre as duas formas de evidência existe a seguinte relação: a reflexão sobre os dados da evidência imediata transforma esta em evidência apodíctica.

Exemplo: a proposição «A representação (na mente) ${ }^{8}$ de um par de objectos é condição necessária de um juízo sobre eles» é tipicamente um juízo apodíctico mas os termos «representação»e «juízo» são para Brentano dados da introspecção.

Husserl, discípulo de Brentano, foi o primeiro crítico da doutrina da evidência apodíctica como irrefutabilidade por meio de um contraexemplo. Para Husserl o facto de um contra-exemplo não ser conhecido é simplesmente contingente, pelo que o carácter apodíctico de um juízo verdadeiro tem que ser derivado da percepção da estrutura que os conceitos que ocorrem no juízo representam. A evidência apodíctica de uma proposição tem que resultar da análise do papel dos conceitos para a definição da estrutura. E é esta análise (e não a inexistência do contra-exemplo) que produz a evidência apodíctica com que a verdade da proposição é conhecida.

Deve-se reparar que um conceito como «percepção da estrutura» pertence ao vocabulário do platonismo de Husserl e é por isso inconsistente com o programa empirista de Brentano, de recondução do conhecimento à experiência. ${ }^{9}$

${ }^{8}$ «Representação» pretende ser uma tradução do termo de Brentano Vorstellung. Há uma disparidade de traduções deste termo, importante no vocabulário de Brentano e no vocabulário finitista de Hilbert. Os objectos em sentido finitista têm que ter Vorstellbarkeit, pelo menos em princípio, i.e., têm que ser representáveis (na mente).

${ }^{9}$ A posição de Gödel em «O que é o problema do Contínuo de Cantor?» é obviamente congruente com a de Husserl. Os axiomas da teoria dos conjuntos, diz Gödel, impõe-se-nos como verdadeiros, constituem por isso um exemplo de 
Para a extracção do significado filosófico de uma teoria matemática dispõe-se essencialmente de duas linguagens: a linguagem da ontologia, com a qual se analisa a questão da existência e a da natureza dos objectos da teoria, e a linguagem da epistemologia, com a qual se determina o género e o grau de conhecimento obtido na teoria.

Gödel, em textos como «A Lógica Matemática de Russell» e «O que é o problema do Contínuo de Cantor?», situa-se num ponto de vista ontológico, dentro do qual toma posição a favor do platonismo ou da existência real dos objectos matemáticos. Mas mesmo quando se adopta um ponto de vista unilateralmente ontológico como forma preferida de análise, problemas sobre evidência colocam-se inevitavelmente, quer durante a descoberta de novos axiomas, quer na justificação de axiomas existentes, quer na reflexão e na arbitragem de axiomas duvidosos. Em particular, um conceito adequado de evidência deve permitir responder ao seguinte catálogo de problemas: ${ }^{10}$

P1 Numa demonstração existem diferenças interessantes entre os símbolos no papel e os pensamentos que eles representam?

P2 Se se foi convencido por uma demonstração indutiva de uma proposição $(\forall n) 2^{n}+2^{n}=2^{n+1}$, é a evidência a que se faz apelo na demonstração finitista?

P3 Em que é que se pensa quando se pensa $a^{n}$ ?

P4 Compreender uma demonstração como uma demonstração $\Delta$ ( $\Delta$ pode ser substituído por «intuicionista», «formalista», ou «finitista»). É empiricamente decidível se se está consciente de compreender uma demonstração como uma demonstração $\Delta$ ?

P5 Existe um acto de compreensão $\Delta$ ?

O ponto de vista da epistemologia ${ }^{11}$ é tomado por Gödel essencialmente nos seus trabalhos de $1933,{ }^{12}$ sobre a aritmética intuicionista,

evidência apodíctica. Este facto permite inferir a existência subjacente de uma percepção, uma vez que se não tivéssemos uma percepção dos objectos da teoria dos conjuntos não faria sentido constatar que, para tais objectos, os axiomas se impõem como verdadeiros. Este conceito de uma percepção inferida é uma construção por analogia, a partir do conceito de percepção de um objecto material.

${ }^{10}$ Soluções para P1 e P3 em Kreisel 1967.

${ }^{11}$ O ponto de vista epistemológico (e o seu vocabulário básico) foi introduzido em Hilbert-Bernays, I, 1934, onde é descrito como «O Problema da Evidência» (Das Evidenzproblem) o qual consiste em avaliar a diferença de evidência que resulta quando se transita de percepções concretas para reflexões abstractas. Para satisfazer 
1942 sobre os limites do conceito intuicionista de evidência, 19581972 sobre uma extensão do ponto de vista finitista por meio de funcionais recursivos. É nestes trabalhos que é posta em acção a teoria (implícita) da evidência de Gödel. Embora não seja possível explicitar completamente uma tal teoria, é possível no entanto reconhecer que a concepção de Gödel se orienta pelos princípios seguintes:

i) A meta a alcançar por uma teoria matemática é para além da verdade a evidência.

ii) Existe uma hierarquia de teorias por graus de evidência. ${ }^{13}$

iii) A evidência de uma teoria diminui à medida que se introduz quantificação universal sobre classes de objectos intensionais (exemplo: «Todas as demonstrações intuicionistas tais que $F(d) »$.)

Os trabalhos de 1958 e 1972 têm o mesmo objectivo estratégico, em nome de um acréscimo de evidência traduzir a aritmética intuicionista no sistema T, mas diferem um pouco na execução. Em 1972 os termos especialmente interessantes de 1958 para a filosofia da evidência foram eliminados ${ }^{14} \mathrm{e}$, embora o novo texto não altere a concepção

o ponto de vista finitista em termos de evidência tem que se exigir que numa definição finistista, i) os objectos sejam sempre representáveis (na mente) e que ii) os processos sejam sempre realizáveis. Kronecker satisfaz o ponto de vista finitista mas o Intuicionismo já é uma extensão.

12 «Zur intuitionistischen Arithmetik und Zahlentheorie», Ergebnisse eines mathematischen Kolloquiums, 4, 1933.

${ }^{13}$ Só dentro da teoria finitista se podem reconhecer os seguintes (por ordem descendente): A) Uma construção que não depende de condições e que se pode visualizar imediatamente como uma totalidade acabada. Exemplo: $2+2=4$. B) $10^{3}+2=1002$. Aqui já não se exige a construção real de $10^{3}$; bastará mostrar que $10^{3}+2=(1000+1)+1=1002$. C) $a+2=2+a$. Já é uma proposição universal e assim interpretada como sendo a asserção: «é conhecido um método geral de construção o qual aplicado a um número natural já construído a permite a construção da igualdade». D) Provar propriedades de números naturais a partir de uma condição da qual não se sabe se pode vir a ser satisfeita.

${ }^{14}$ Embora Gödel declare na nota $a$ de 1972 que o texto inglês não é uma tradução literal, algumas das liberdades de tradução constituem um problema interpretativo: i) pp. 272, 273, 274, «concrete intuition» ocorre como tradução da expressão hilbertiana anschauliche Evidenz. Ainda que se possa aceitar «concerte» como tradução de anschaulich, não se pode aceitar «intuition» como tradução de Evidenz, uma vez que a intuição é uma faculdade mental e a Evidência é uma propriedade de um juízo verdadeiro. ii) p. 275 , a definição crucial foi reformulada tendo sido eliminada 
original, nesta o acto de compreensão necessário para compreender a definição de funcional deixa de ser explícito. Mas esses termos são essenciais para decidir se é uma questão empírica determinar se se está consciente de estar a compreender uma definição como uma definição construtiva (Problema 4, acima). É claro que uma resposta positiva implica a aceitação da existência do acto de compreensão construtivo (Problema 5).

Em 1958 Gödel confronta-se com questões de evidência em dois momentos, um primeiro momento durante o relato e a análise do insight de Hilbert-Bernays, segundo o qual a evidência intuitiva é insuficiente para a demonstração da consistência da aritmética e que tem por isso de ser suplementada pela evidência abstracta e, num segundo momento, durante o esboço da arquitectura do sistema $T$, com a separação entre o acto intencional da compreensão do sentido do conceito de função calculável de tipo finito e a evidência dos axiomas propostos para $T$.

O significado histórico de 1958 reside no facto de Gödel reabilitar o conceito tradicional de evidência, mesmo perante um ambiente circundante hostil. ${ }^{15}$ Em 1958 a epistemologia e a filosofia da mente então dominantes eram em primeiro lugar, desde os Principia Mathematica, contra a existência de relações internas, em segundo lugar, desde o Círculo de Viena, a favor da eliminação de relações intensionais na teoria unificada da ciência e, em terceiro lugar, desde as Investigações Filosóficas de Wittgenstein a favor de um behaviorismo encapotado.

Mas logo a definição (informal) de evidência abstracta de Bernays, adoptada por Gödel em 1958, subscreve a adopção de um princípio de intensionalidade, implicando assim o conhecimento de objectos mentais, como demonstrações intuicionistas ou o sentido de proposições, bem como a existência de relações internas e a fiabilidade da intuição.

Assim o seu trabalho de 1958 não se insere na epistemologia oficial do Círculo de Viena, onde Schlick e Carnap consideraram o concei-

a referência ao acto de compreensão dos conceitos «função computável de tipo $t_{i}$ » $(i=0,1, \ldots, k)$. A frase da linha 6 da mesma página «this general fact is constructively evident» é ambígua: o que tem que ser construtivamente reconhecível é que a operação é sempre possível. iii) p. 276, os axiomas deixam de ser apresentados como evidentes.

${ }^{15}$ A título de comparação: em 1994, The Oxford Dictionary of Philosophy, de Simon Blackburn, não tem uma entrada «evidência», apesar da abundante escolha de temas em epistemologia. 
to de evidência como destituído de sentido e uma faculdade de intuição como inexistente, como também não se insere nem na epistemologia naturalista de Quine nem na filosofia da mente de Wittgenstein. A linha de investigação epistemológica que através de Bernays chegou a 1958 provém da orientação anti-kantiana e neo-escolástica dominante no Império Austríaco associada com os nomes de Franz Brentano e mais tarde de Edmund Husserl.

M. S. Lourenço Universidade de Lisboa

\section{Bibliografia}

Bernays, P. 1935. Sur le Platonisme dans les Mathématiques. L'Enseignement Mathématique, 34.

1959-1960. Ludwig Wittgensteins 'Bemerkungen über die Grundlagen der Mathematik.' Ratio 2.

Brentano, F. 1874. Psychologie vom empirischen Standpunkt, Leipzig.

1930. Wahrheit und Evidenz, Leipzig.

1929. Über die Zukunft der Philosophie, Leipzig.

Brouwer, L. 1948. Consciousness, Philosophy and Mathematics. Proc. $X^{\text {th }}$ International Congress of Philosophy, Amsterdam.

Chisholm, R. 1960. Realism and the background of phenomenology. Illinois.

Day, S. 1947. Intuitive Cognition, A Key to the Significance of the later Scholastics. New York.

Dummett, M. 1993. Origins of Analytical Philosophy. Harvard University Press.

Gilson, E. 1952. Jean Duns Scot. Paris.

Gödel, K. 2001. Collected Works, ed. S. Feferman et al. Oxford.

Hilbert-Bernays. 1939. Grundlagen der Mathematik, vol. I. Berlin.

Husserl, E. 1891. Philosophie der Arithmetik, Halle.

— 1938/1939. Die Frage nach dem Ursprung der Geometrie als intentionalhistorisches Problem. Revue Internationale de Philosophie, vol. 1.

Kneale, W. \& M. 1972. O Desenvolvimento da Lógica. Trad. M. S. Lourenço, Lisboa.

Kreisel, G. 1967. Mathematical Logic: what has it done for the philosophy of mathematics? Bertrand Russell, Philosopher of the Century, ed. R. Schoenman, London.

1970. Die formalistisch-positivistische Doktrin der mathematischen Präzision im Lichte der Erfahrung. Zentralblatt für Mathematik und ihre Grenzgebiete, 196.

Ockham, W. 1675. Summa Totius Logicae, Oxford. Ed. moderna por P. Boehner, New York, 1945.

Wang, H, 1988. Reflections on Kurt Gödel. Massachusetts Institute of Technology. 